Cremer, A. W. F. (1968). Automatic slide staining in clinical bacteriology. Journal of Medical Laboratory Technology, 25, 387-390.

Preston, N. W., and Morrell, A. (1962). Reproducible results with the Gram stain. Journal of Pathology and teriology, 84, 241-243.

Spencely, M., Parker, M. J., Dewar, R. A. D., and Miller, D. L. (1979). The clinical value of microbiological laboratory investigations. Journal of Infection, 1, 23-36.

Requests for reprints to: Dr D. A. McSwiggan, Public Health Laboratory, Department of Microbiology, Central Middlesex Hospital, Park Royal, London NW10 7NS, UK.

\section{A method of highlighting the macroscopic patterns of congenital cystic kidneys}

\author{
J. T. LIE Department of Pathology and Anatomy, \\ Mayo Clinic and Mayo Foundation, Rochester, \\ Minnesota, USA
}

The cut surface of a congenital cystic kidney can be graphically displayed by a simple impregnation technique using barium sulphate, a method that has been used for the study of emphysematous lung. The specimen so treated is valuable for pattern recognition and morphometric studies of cystic kidneys.

Morphological studies of pulmonary emphysema have benefited greatly by many refined laboratory innovations during the last 20 years; among these are Gough's (1968) technique of paper-mounted sections and Heard's (1960) techniques of perfusion and barium sulphate impregnation.

The barium sulphate impregnation technique is particularly useful in 'pattern recognition' of the gross appearance of the cut surface of the lung. After repeated sequential treatment of the specimen in barium nitrate and sodium sulphate solutions, the walls of distended air-spaces in emphysematous lung become coated by precipitated barium sulphate and are conspicuously displayed. Simplicity and effectiveness are the two most appealing features of this technique.

Cyst formation is a common morphological feature of the many different varieties of renal dysplasia and polycystic disease of the kidney, and characterisation of the individual types of these anomalies is often possible by gross examination of the cut surfaces of the kidney (Kissane and Smith, 1967). For this purpose we have found that the barium sulphate impregnation technique has many advantages. The spongy nature of many of these kidneys created by the innumerable cystic spaces of different sizes bears some resemblance to emphysematous lungs. By the use of a technique similar to that described by Heard (1960) for the studies of lungs, an equally striking specimen of the cut surface of a cystic kidney also can be produced by barium sulphate impregnation (Figure). The specimen so prepared is particularly valuable for teaching purposes and for morphometric studies.

The sagittal section of the kidney is first fixed in phosphate-buffered neutral $10 \%$ formaldehyde, either by total immersion of the specimen or by a

Received for publication 11 June 1979 


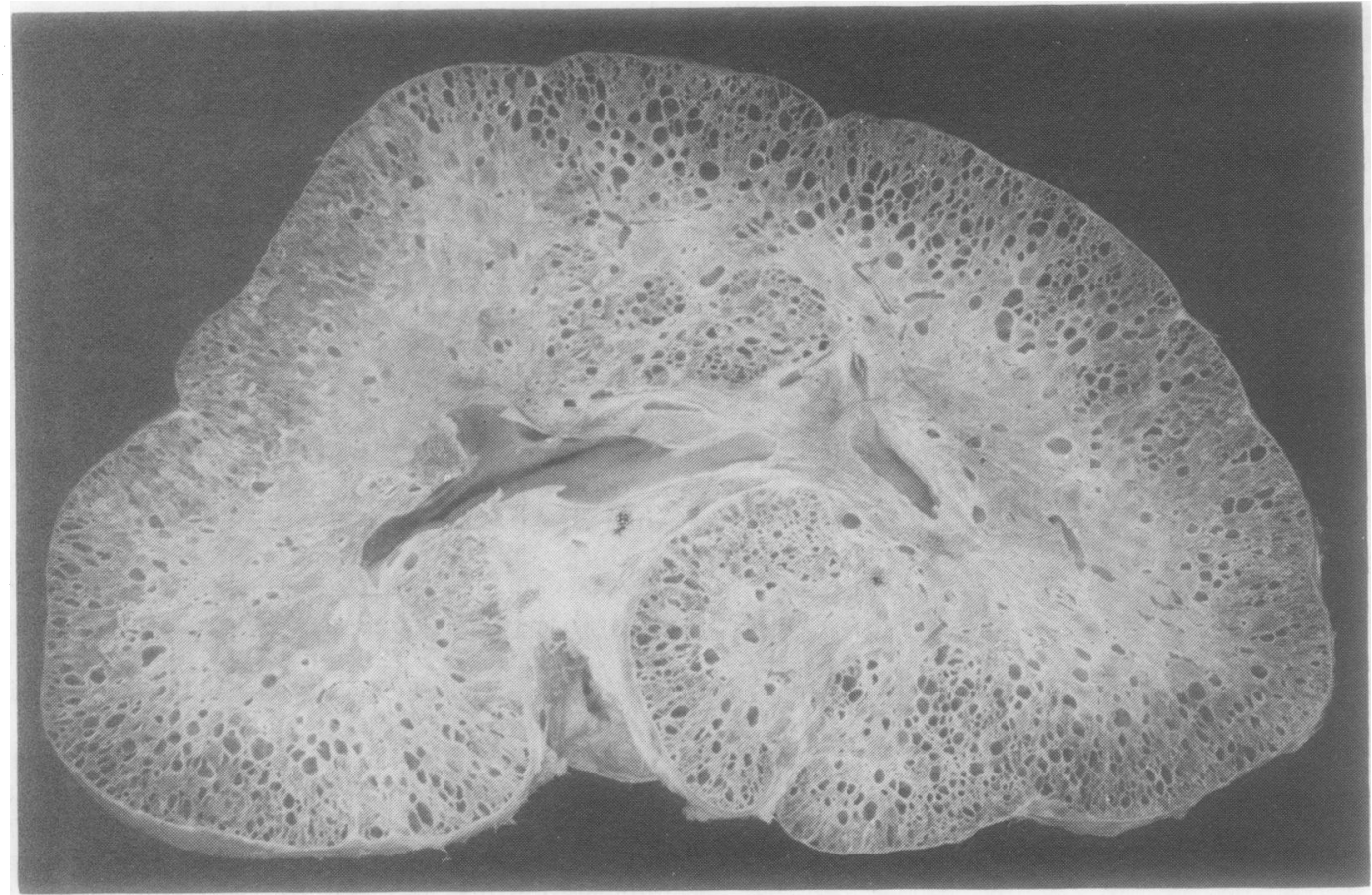

Sagittal cut surface of infantile-type polycystic kidney showing macroscopic pattern of cysts to advantage after the barium sulphate impregnation treatment.

perfusion process; the tissue fixative is injected into both the arterial and venous channels of the kidney and into the ureter or ureters. The fixed specimen is then submerged in a $7.5 \% \mathrm{wt} / \mathrm{vol}$ solution of barium nitrate, and the specimen is gently squeezed to aid penetration of the chemical. After about 3 to 5 minutes the specimen is removed from the barium nitrate solution and the excess fluid is drained and expressed.

The specimen is then submerged in a $10 \% \mathrm{wt} / \mathrm{vol}$ solution of sodium sulphate and gently squeezed to increase the absorption of the chemical. After about 3 to 5 minutes the specimen is removed from the sodium sulphate solution, and the excess fluid is drained and expressed.

Repeating this simple cycle of submersion in barium nitrate and sodium sulphate solution three to five times increases the formation of the greyish- white barium sulphate precipitate and results in a satisfactorily impregnated specimen.

\section{References}

Gough, J. (1968). Twenty years' experience of the technic of paper mounted sections. In The Lung, edited by A. A. Liebow and D. E. Smith, pp. 311-316. Williams and Wilkins, Baltimore.

Heard, B. E. (1960). Pathology of pulmonary emphysema: methods of study. American Review of Respiratory Diseases, 82, 792-799.

Kissane, J. M., and Smith, M. G. (1967). Pathology of Infancy and Childhood, pp. 521-541. C. V. Mosby, St. Louis.

Requests for reprints to: Dr J. T. Lie, Department of Pathology and Anatomy, Mayo Clinic. Rochester. Minnesota 55901, USA. 